\title{
Falsificación de documentación monástica en la Edad Media: Santa María de Nájera *
}

\author{
The falsification of monastic records in the Middle Ages: Santa \\ María de Nájera
}

\author{
Margarita Cantera Montenegro **
}

\begin{abstract}
RESUMEN
Durante la Edad Media, y especialmente en los primeros siglos, fue muy frecuente

falsificar documentos, retocando los existentes en unos casos o creándolos de nuevo en otros, a veces para dar fe escrita de un acto jurídico no reflejado en su momento en un documento. En este trabajo, además de hacer unas consideraciones generales, se analizan algunos de los documentos reales del monasterio de Santa María de Nájera que, sin duda, han sido falsificados de una manera más o menos amplia.
\end{abstract}

\section{PALABRAS CLAVE}

Documentación medieval, historia de la Iglesia, monasterios medievales, Orden de Cluny en Castilla.

\begin{abstract}
During the Middle Ages, and especially in its first centuries, the falsification of documents was quite common -original records being modified in certain cases, or new documents being forged altogether in others - often to attest in writing a missing legal clause. In this study, as well as making some general considerations on the issue, we will analyze a group of royal documents of the monastery of Santa María de Nájera which have been, in some evident way, falsified.
\end{abstract}

\section{KEY WORDS}

Medieval documentation, the history of the Church, medieval monasticism, the Order of Cluny in Castile.

\footnotetext{
* Fecha de recepción del artículo: 2012-6-13. Fecha de aceptación del artículo: 2012-10-13.
}

Este trabajo se ha elaborado en el marco del Grupo de Investigación consolidado de la Universidad Complutense 930369: «Sociedad, poder y cultura en la Corona de Castilla, siglos XIII al XVI», dirigido por los profs. D. Miguel Ángel Ladero Quesada y D. José Manuel Nieto Soria. La iniciativa para la elaboración de este artículo surgió de la participación en la Mesa Redonda Falsificaciones medievales celebrada en noviembre de 2011, en el marco de la Semana de la Ciencia, siendo el coordinador de dicha Mesa el prof. Martín Prieto.

** Universidad Complutense de Madrid. C.e.: mcantera@ghis.ucm.es 
Según afirma el prof. Escalona ${ }^{1}$, en la Edad Media se falsificaba y se hacía en abundancia, incluso a pesar de que se trataba de un delito castigado por la ley, y con dureza en ciertos supuestos. Si la falsedad es un elemento común a muchos documentos, existe una gran variedad entre los textos falsificados ${ }^{2}$ : unas veces la falsificación tenía miras elevadas, mientras que en otras eran rastreras. En ocasiones eran formalmente torpes, y no extraña que ya en su momento despertaran sospechas o fueran inmediatamente rechazadas; mientras que en otras eran tan perfectas que incluso en la actualidad resulta difícil descubrirlas. Unas consiguieron el objetivo deseado, mientras que otras fracasaron al intentar darles cumplimiento.

Pero antes de seguir adelante habría que matizar qué se entiende por documento falso, ya que este epíteto esconde una realidad multiforme. Habría que diferenciar entre documentos que son falsos en su contenido, el falso histórico, o aquellos cuyo contenido es auténtico, pero no lo es en la forma en que ha sido redactado, el falso diplomático o formal.

$\mathrm{Si}$, evidentemente, la utilidad para el historiador de este último tipo es grande, ya que la veracidad del contenido es lo que principalmente debe interesar, tampoco debemos escatimar la importancia de los otros falsos, los falsos históricos, pues obligan al historiador a analizarlos no tanto en su aspecto formal como en el trasfondo del texto, obligando a buscar la razón de la falsificación, el por qué se elaboró, las intenciones del autor, los recursos de que dispuso, la forma en que apela a los elementos que podrían dar verosimilitud a su contenido y permitieron en algunos casos tener una aceptación tan amplia ${ }^{3}$. Y ello a pesar de que, como ha indicado la prof. Sanz Fuentes ${ }^{4}$, los historiadores, especialmente después de los trabajos hipercríticos de Barrau-Dihigo sobre los documentos de los reyes asturianos, han denigrado los documentos falsos, considerándolos tan sólo el fruto de una falacia, pero sin distinguir esos dos tipos de falsificación antes reseñados ni plantearse cuál fue el motivo de la falsificación.

Pero, volviendo a la distinción entre los dos tipos antes señalados, tendríamos que plantearnos si es correcto para el historiador considerar falsos aquellos documentos que lo son sólo en la forma, cuando el contenido o lo más sustancial del mismo no se ha modificado; sobre todo teniendo en cuenta que la mayoría de los textos diplomáticos de la primera Edad Media, y hasta los siglos XII o XIII, nos han

\footnotetext{
1 Julio ESCALONA MONGE, «Lucha política y escritura: falsedad y autenticidad documental en el conflicto entre el monasterio de Santo Domingo y el burgo de Silos (siglos XIII-XIV)", en Conflictos sociales, políticos e intelectuales en la España de los siglos XIV y XV. XV Semana de Estudios Medievales de Nájera, Logroño, 2004, p. 215.

2 Idem, ibidem.

3 Idem, ibidem, pp. 214-215.

4 «El lenguaje de los documentos falsos», en Orígenes de las lenguas romances en el reino de León. Siglos IX-X, I, León, 2004, pp. 119-120; y "Cartularios: historia y falsificación histórica», en La memoria histórica de Cantabria, Santander, 1995, p. 151. También es interesante Pilar OSTOS y $\mathrm{M}^{a}$ Luisa PARDO, «La teoría de la falsedad documental en la Corona de Castilla», en Falsos y falsificaciones diplomáticas en la Edad Media, Zaragoza, 1991, pp. 161-175.
} 
llegado por medio de copias, lo que siempre arroja dudas acerca de la versión original y la mayor o menor fidelidad del copista. No podemos olvidar que la labor de éste siempre se encontraba en tensión entre el objetivo de transmitir fielmente el texto que copiaba y la inclinación natural a reproducir hábitos lingüísticos propios $^{5}$ o a corregir errores; o lo que él creía que se trataba de errores. En algunas ocasiones el copista introdujo voluntariamente rasgos arcaicos en el texto que transcribía para dar mayor autoridad a la copia imitando una antigüedad que no tenía; en este caso, hay que pensar no en una copia simple, sino en la clara intención de hacer pasar como original un texto que no lo es.

$\mathrm{Y}$, por supuesto, no podemos olvidar los errores propios de la copia, como pueden ser la omisión de una palabra, la repetición de otra u otras, el salto de una línea ${ }^{6}$; o las omisiones intencionadas, como las que señala el prof. Fernández Flórez, y que posiblemente se deben a la incapacidad del copista de leer ciertas palabras, especialmente los nombres de los testigos, o de interpretar algunos signos o abreviaturas ${ }^{7}$. Incluso algunos «errores» se explicarían porque no se trata realmente de una copia, sino de un documento que se rehizo o reelaboró de memoria, sin tener el original presente.

En muchos casos los documentos rehechos tenían como objeto restituir un texto perdido o evitar su posible destrucción por cualquier desastre, natural o no (incendio, inundación, robo...). Es cierto que al rehacer el documento se pueden modificar los elementos externos, y de hecho se hacía, quizás con el deseo de mejorar la calidad literaria o para refundir en uno varios documentos de contenido semejante o emitidos por un mismo otorgante ${ }^{8}$; asimismo, se podían introducir interpolaciones o añadidos para enriquecer, aunque sea formalmente, el texto original o acercarlo más a la forma que tendría de haber sido redactado en el momento en que se reelaboró ${ }^{9}$.

\footnotetext{
5 Mónica CASTILLO LLUCH, «La impostura lingüística: intervención de copistas, editores y gramáticos en los textos medievales», en Cahiers d'études hispaniques médiévales, 29 (2006), pp. 498. Como indica el título, analiza la cuestión especialmente desde la perspectiva lingüística, prestando también atención a las correcciones que en ocasiones introducen los editores de textos medievales.

Tomás Puñal Fernández (El guardián de Somosierra. El monasterio de Santo Tomé del Puerto a través de sus documentos (Siglos XII-XV). Estudio histórico, archivístico y diplomático y colección diplomática, Palencia, 2012, p. 99) señala cómo muchas alteraciones son fonéticas o gramaticales debidas a la adaptación lingüística que surgía por disociación entre el latín del documento y la lengua romance que se hablaba, por la propia evolución del latín e, incluso, porque el copista escribía tal como pronunciaba.

6 Estas alteraciones externas también podían ser de adaptación lingüística, sustituyendo unas palabras por otras con parecido o idéntico significado, según indica Tomás PUÑAL FERNÁNDEZ, Op. Cit., p. 99.

7 «La huella de los copistas en los Cartularios leoneses», en Orígenes de las lenguas romances en el reino de León. Siglos IX-X, I, León, 2004, p. 200-201.

8 Ma. J. SANZ FUENTES, “Cartularios», p. 151. Este caso es muy frecuente en el Liber Testamentorum de la Catedral de Oviedo.

9 Es cierto que desde antiguo existen sistemas regulados por medio de la autoridad competente para sustituir documentos desaparecidos, desde la legislación visigoda a las Partidas de Alfonso X el Sabio. Pero también es cierto que muchas de las reelaboraciones de documentos tiene un carácter «particu-
} 
Si nos centramos de lleno en los documentos falsos absolutos o históricos, deberíamos también diferenciar entre hacer un documento falso, es decir, fabricar uno que no ha existido nunca, o falsificar un documento ya existente, suprimiendo o añadiendo algo a uno verdadero. De conservarse el documento original, el falsario, una vez elaborada la nueva redacción, podía conservar el texto antiguo o, con más frecuencia, destruirlo para evitar que se descubriese el engaño o se aplicase la redacción «antigua», quizás menos beneficiosa para el interesado.

Generalmente se falsificaban documentos importantes, como pueden ser bulas pontificias, concesión de indulgencias, actas de fundación de monasterios, textos jurídicos...

En cuanto al objetivo de los falsificadores, que siempre tenían el deseo de dotar de validez permanente al texto fabricado, podía ser variado. Muchos de ellos perseguían un fin utilitario muy claro: procurar al cliente ventajas personales de diverso carácter, como apoyar la vanidad y el orgullo (pensemos, por ejemplo, en la falsificación de las genealogías y libros de linaje), servir intereses políticos o sociales o reportarle ventajas económicas ${ }^{10}$.

Otros, sin embargo, podrían ser calificados de «falsarios honestos» ${ }^{11}$, pues su intención sería sólo hacer valer unos derechos legítimos cuando el documento original se había perdido o destruido; o incluso en el caso de que nunca hubiera existido por tratarse de un acuerdo verbal, algo muy frecuente en la Edad Media. Es evidente que se está transformando una situación de hecho en una de derecho; pero también lo es que el objetivo era contar la realidad sin cambiar el contenido del acto descrito. Por ello, Huber Silvestre ${ }^{12}$ solicita indulgencia hacia cierta categoría de documentos falsos, como títulos de propiedad territorial o documentos similares que algunas personas o instituciones elaboraron para «recuperar» documentos anteriores, pensando en la necesaria reconstrucción de los archivos tras los saqueos provocados por alguna de las frecuentes violencias del período (incursiones vikingas en el norte de Europa, invasión y saqueo de los musulmanes en los monasterios españoles...) o las pérdidas debidas a catástrofes naturales.

\footnotetext{
lar» o "casero", sin recurrir a los medios legales establecidos, por considerar que no era necesario un proceso complejo o que requería acudir a diversas autoridades.

El documento original puede definirse como la pieza documental que se conserva, en sus caracteres internos y externos, tal como fue emitido por su autor (M. ROMERO TALLAFIGO, «La tradición documental. Originales y copias", en Archivística, Sevilla, 1981, p. 69;T. MARÍN MARTÍNEZ, Paleografía y Diplomática, 2, Madrid, 1991, 5ae ed., p. 249; J.A. FERNÁNDEZ FLÓREZ, "La huella de los copistas", p. 162); aunque original no significa obligatoriamente que sea documento único, pues hay contratos que tienen dos o más originales o documentos con varios destinatarios y que se emitían en forma múltiple.

10 O. GUYOTJEANNIN, J. PYCKE y B.-M. TOCK, Diplomatique médiévale, [Turnhout, Belgium], 1993 p. 372.

11 Idem, ibidem.

12 «Le problème des faux au Moyen Age (A propos d'un livre de M. Saxer)», en Le Moyen Âge, 66 (1960), p. 363.
} 
En este caso, hay que insistir en que nos encontramos realmente ante documentos rehechos, falsos formalmente, pero auténticos en su contenido.

Todo esto nos lleva a plantear si era tan fácil fabricar y falsificar un documento en la Edad Media. Y la respuesta es que sí, al menos hasta el siglo XIII, pues no había sistemas de registro sistemático que permitiesen verificar la veracidad de los documentos ${ }^{13}$. Por otra parte, como ya he señalado, la mayoría de los procedentes de la Alta Edad Media nos han llegado a través de copias ${ }^{14}$, incluso aunque a veces no se muestren como tales; es decir, nos encontraríamos ante falsos diplomáticos, aunque ello no obliga a dudar de la veracidad de su contenido.

Para detectar la falsificación de un documento hay que utilizar diversos medios, como comparar el tipo de escritura, las fórmulas empleadas, la posible existencia de incoherencias cronológicas (aunque a veces pueden deberse a errores), incorrecciones léxicas o jurídicas, el sistema de datación, etc. Por todo ello, para detectar la falsedad, formal o absoluta, se debe conjugar el trabajo del historiador, del diplomatista y paleógrafo, del filólogo, del historiador del Derecho, del latinista ${ }^{15}$.

Varios eran los sistemas que se podían utilizar para falsificar un documento, como cambiar una palabra por otra, raspando o sobrescribiendo sobre el texto original; por ello, los escribanos y notarios tenían mucho cuidado de anotar y señalar si hacían alguna corrección o añadido, para evitar la duda de si se trataba de una corrección por error o lo era por la mala voluntad de modificar el original ${ }^{16}$ También se podían introducir tachaduras estratégicamente situadas que hiciesen ininteligible una frase, simulando un «accidente» (un manchón de tinta o una mancha en el pergamino ${ }^{17}$ ). En otras ocasiones se cambiaba voluntariamente, se añadía o suprimía, alguna palabra o frase; por ejemplo, se podía sustituir algún nombre de persona o, si se trataba de cantidades, añadir o suprimir alguna cifra.

Cuando se había fabricado un documento nuevo, tanto si era una copia fiel de uno perdido como especialmente si se trataba de una invención o modificación

${ }^{13}$ GUYOTJEANNIN, op. cit., p. 372. En el caso de Castilla, el estudio de las Cancillerías regias interesó ya a A. MILLARES CARLO, «La cancillería real en León y Castilla. Hasta el final del reinado de Fernando III», en Anuario de Historia del Derecho Español, III (1926), pp. 227-307. Más recientemente se ha abordado el análisis de las cancillerías de Fernando III y, especialmente, de Alfonso X: Pilar OSTOS SALCEDO, «La cancillería de Fernando III, rey de Castilla (1217-1230). Una aproximación», en Archivo Hispalense: Revista histórica, literaria y artística, 77 (1994), pp. 59-70; Antonio José LÓPEZ GUTIÉRREZ, «La Cancillería de Fernando III, Rey de Castilla y León (1230-1253)», en Archivo Hispalense: Revista histórica, literaria y artística, 77 (1994), pp. 71-82; e idem, La Cancillería de Alfonso $X$ a través de las fuentes legales y la realidad documental, Oviedo, 1990.

${ }_{14}$ Guyotjeannin señala que más de la mitad de los documentos de los reyes merovingios son, en este sentido, falsos. Y lo mismo podríamos decir de los documentos asturleoneses altomedievales, lo que llevó a ese hipercriticismo antes señalado de algunos autores, como Barrau-Dihigo.

15 GUYOTJEANNIN, op. cit., p. 375-378. J.A. FERNÁNDEZ FLÓREZ, Op. cit., p. 162-163.

${ }^{16}$ En el primer caso, es habitual señalar la corrección con frases como ay raydo o ay emendado o entre renglones diz... vala e non le empesca.

17 GUYOTJEANNIN, op. cit., p. 373. 
importante, el «falsario» intentaba obtener la validación oficial del texto, solicitando a la cancillería regia la confirmación del privilegio elaborado; si la confirmación era concedida, se otorgaba plena validez jurídica al acto documental. Esto fue muy frecuente en el caso de la documentación monástica, especialmente respecto a las cartas de fundación y donación realizadas por los monarcas anteriores, solicitudes que se hacían habitualmente al inicio de un reinado para garantizar la continuidad de los privilegios; se trataba de una práctica a menudo formularia, y de la que no conocemos bien con qué rigor se llevaría a cabo en la cancillería regia ${ }^{18}$.

En todo caso, tenemos que insistir en que la existencia en un documento de un pasaje interpolado no prueba la falsedad de todo el texto; e incluso que un documento falso absoluto sigue siendo útil para determinados estudios, aunque quizás no lo sea para todos ${ }^{19}$.

Hubo ciertas situaciones más propicias para la falsificación documental, como una guerra, o momentos de crisis política o un cambio de dinastía en el trono, cuando los monarcas buscaban asegurar fidelidades por cualquier medio; y la confirmación de privilegios podía ser uno de ellos.

En este sentido, se ha señalado que en los siglos X al XIII se produjeron abundantes falsificaciones documentales en los monasterios castellano-leoneses, hecho que se explica por diversos factores ${ }^{20}$ : la revalorización del documento escrito como credencial de autenticidad y permanencia de actos jurídicos; la aceptación social de la prueba escrita como testimonio de lo verdadero, cuando anteriormente predominaba el símbolo y la palabra; el cambio de la letra visigótica a la carolina; el deseo de afirmar los privilegios jurisdiccionales en el momento de su consolidación y, en general, todos los derechos de la institución, asegurando o mejorando las condiciones de los mismos. Por todo ello, si no existía el documento, porque quizás no se escribió en su momento, era necesario fabricarlo sobre la memoria y tradición del acto realizado.

Al hablar de la documentación monástica hay que recordar que buena parte de la misma se ha conservado en cartularios o recopilaciones de textos elaborados en una época posterior, con carácter exhaustivo o selectivo. Si estos textos han asegurado su conservación y facilitado su consulta, siempre está presente el inconveniente de que se trata de copias; es decir, se han podido introducir modificaciones por error, por querer actualizar el lenguaje, por dificultad de leer algunos

\footnotetext{
18 Consta que en algún caso se negó la confirmación y en otros se establecieron reservas sobre alguna parte de su contenido (J. ESCALONA, Lucha política, p. 219).

19 J.A. FERNÁNDEZ FLÓREZ, op. cit., p. 161-163.

20 J.A. GARCÍA DE CORTÁZAR, «Monasterios románicos de Castilla y conservación de la memoria histórica», en Monasterios románicos y Producción Artística, Aguilar de Campóo, 2003, p. 18-19. L.A AGÚNDEZ SAN MIGUEL, «Escritura, memoria y conflictividad entre el monasterio de Sahagún y la catedral de León: nuevas perspectivas para el aprovechamiento de los falsos documentales (siglos X a XII)», en Medievalismo, 19 (2009), pp. 269-270.
} 
pasajes o palabras... ${ }^{21}$ A pesar de ello, los Cartularios nos han transmitido copias o extractos de muchos documentos de los que el original se ha perdido, por lo cual su valor es inmenso desde el punto de vista histórico, aunque, lógicamente, no tenga el mismo para el paleógrafo o para el diplomatista.

En la falsificación documental pudieron influir otros muchos factores, siendo importantes a menudo los que podemos calificar de políticos. Éste es el caso de algunos textos los monasterios de San Pedro de Arlanza, Santo Domingo de Silos y San Millán de la Cogolla analizados por los profs. Azcárate, Escalona, Jular y Larrañaga: la necesidad de modificar o crear documentos que acercasen la historia de estos cenobios a la persona del conde Fernán González, en un momento de exaltación de esta figura histórica en la Castilla de los siglos XII y XIII ${ }^{22}$.

En esta clave analizan los autores el proceso de falsificación del documento de fundación del cenobio de Arlanza: el conde Gonzalo Téllez de Lantarón había fundado el monasterio el año 912; pero en el siglo XII este conde estaba casi olvidado, mientras crecía la fama de Fernán González como héroe de la independencia castellana. Por ello, en el tercer cuarto del siglo XII se elaboró un nuevo documento fundacional imitando al auténtico en su caligrafía y con muy pocas variaciones en su contenido, aunque con una diferencia sustancial: la fundación no se atribuía a Téllez de Lantarón, sino a Fernán González, manteniendo incluso la fecha de 912, imposible para este conde. Cuando en 1255 el rey Alfonso X el Sabio confirmó el texto, entre otros documentos importantes del cenobio y a solicitud de éste, el texto falso se vio refrendado por el poder regio y revestido de legitimidad.

Proceso semejante se señala para el cenobio de Silos. En este caso se puede detectar la falsificación del texto atribuido a Fernán González, y elaborado también en el siglo XII, a través de la precisión con que se describe el coto del cenobio, algo impropio del siglo $X$ en que se dice fue redactado el documento. Respecto a este monasterio, Julio Escalona ${ }^{23}$ señala cómo en el desarrollo de ciertos pleitos entre el cenobio y el concejo de Silos, ambos litigantes pusieron en duda la autenticidad de algún documento presentado por la parte contraria, apelando a argumentos de carácter diplomático: lo consideraban demasiado bien conservado para

21 J. A. FERNÁNDEZ FLÓREZ, op. cit., p. 164-165; en ejemplos concretos señala, por ejemplo, la utilidad del Becerro Gótico de Sahagún para defender el patrimonio monástico y sus derechos tanto frente a señores laicos como ante los obispos (p. 173). $M^{a}$. J. SANZ FUENTES, «Cartularios», p. 147 ss.

${ }_{22}$ P. AZCÁRATE, J. ESCALONA, C. JULAR y M. LARRAÑAGA, «Volver a nacer: historia e identidad en los monasterios de Arlanza, San Millán y Silos (siglos XII-XIII)", en Cahiers d'études hispaniques médiévales, 29 (2006), pp. 359-420. Algunos aspectos de esta creación de la «memoria histórica» de éstos y otros monasterios había sido ya señalada por J.A. GARCÍA DE CORTÁZAR, Op. cit., pp. 20-30, en relación especial con la redacción de crónicas y leyendas en los monasterios; y «Monasterios castellanos, memoria histórica y organización de la sociedad y del espacio en los siglos X a XII», en Silos. Un milenio. Actas del Congreso Internacional sobre la Abadía de Santoa Domingo de Silos. I. Historia (dir. J.A. FERNÁNDEZ FLÓREZ), Silos, 2003, pp. 158-163 (también se refiere a los cenobios de Oña y Cardeña).

23 «Lucha política y escritura», pp. 205-252. En él hace consideraciones generales muy interesantes aplicables a cualquier documentación. 
el tiempo que tendría si fuese verdadero; anomalías formales en el texto; novedad en su alegación, lo que hacía sospechar que antes no existía; diferencias con otros de la época de la que dice proceder, etc. Todos estos elementos indican la existencia en los concejos de personas con conocimientos técnicos para detectar una posible falsificación y para inventar un documento; pero, sobre todo, la posibilidad que tenían, por medio de los escribanos públicos, de valerse de su posición de privilegio en la administración regia.

En cuanto al monasterio de San Millán de la Cogolla, también se intentó buscar algún elemento de unión con el conde Fernán González; y como no era posible a través de la fundación, pues indudablemente se había producido en época visigoda (y tampoco era cuestión de renunciar a esta ennoblecedora antigüedad), se hizo por el texto conocido como los Votos de San Millán, privilegio atribuido al año 934 y a la autoría de dicho conde: éste, en agradecimiento al santo por una sonada victoria contra los musulmanes, habría establecido el pago al cenobio emilianense de una cuota anual que debían satisfacer todos los pueblos de Castilla y algunos de Navarra. Con este texto, además de dar apoyo diplomático y legal al cobro de una contribución hasta entonces basada en la costumbre, se reforzaba la vinculación del monasterio emilianense con Fernán González y con el período fundacional de Castilla ${ }^{24}$.

También podemos hablar de falsificación documental, aunque simplemente formal, en el caso del llamado Becerro Gótico de Sahagún. Se trata de una recopilación de documentos de este cenobio leonés, perteneciente a la Orden de Cluny, elaborada hacia el año 1110 para asegurar los títulos de propiedad del cenobio y facilitar su consulta y conservación. Pero el copista «falsea», desde el punto de vista diplomático, los documentos: no los transcribe íntegros y suprime algunas de las partes formales de los mismos, como las listas de confirmantes y testigos, que él consideraba innecesarias y que no altera el sentido de los textos. A ello hay que añadir los inevitables errores humanos en una copia, así como una posible dificultad por transcribir ciertas palabras y, especialmente, los nombres de persona ${ }^{25}$.

Uno de los códices falsos, desde el punto de vista formal, más famoso es el Liber Testamentorum de la catedral de Oviedo, elaborado entre fines del siglo XI y principios del XII con el objeto claro de defender los derechos de dicha sede, mostrando la antigüedad y legitimidad de todas las exenciones y privilegios de la dió-

\footnotetext{
${ }^{24}$ Además del artículo ya citado de Azcárate, Escalona, Jular y Larrañaga, y la breve pero clara síntesis de GARCÍA DE CORTÁZAR, «Monasterios castellanos», sobre este texto se pueden destacar los estudios siguientes: A. UBIETO ARTETA, "Los "Votos de San Millán" », en Homenaje a Jaime Vicens Vives, Barcelona, 1965 pp. 309-324. B. DUTTON, La «Vida de San Millán de la Cogolla» de Gonzalo de Berceo, Londres, 1967, en diversas páginas al relacionar este texto con la obra del poeta berciano. F.J. GRANDE QUEJIGO, Hagiografía y difusión de la «Vida de San Millán de la Cogolla» de Gonzalo de Berceo, Logroño, 2000, con el mismo motivo que el trabajo anterior.

25 FERNÁNDEZ FLÓREZ, Op. cit., pp. 172-174.
} 
cesis; ello explica el lujo y belleza formal del códice ${ }^{26}$. El autor del Liber se trata, casi con total seguridad, del obispo Pelayo, acusado de falsario por haber modificado la trasmisión de los textos en su aspecto formal: eliminó los pasajes que consideraba inútiles, corrigió los errores en la gramática latina de los textos originales, uniformó las fórmulas documentales con una redacción más sobria, refundió en una pieza diversas documentos (por ejemplo, las donaciones realizadas a la catedral por un mismo monarca) o introdujo aclaraciones o interpolaciones que, realmente, no alteran el sentido original del documento, aunque, eso sí, desde el punto de vista diplomático lo falsifican.

\section{LA FALSIFICACIÓN DOCUMENTAL REFERIDA AL MONASTERIO DE SANTA MARÍA DE NÁJERA²7}

Este monasterio riojano fue fundado en 1052 por el monarca pamplonés García III, conocido como el de Nájera. Cuando La Rioja se incorporó a Castilla en 1076, Alfonso VI entregó esta iglesia y sus propiedades a la Orden de Cluny. Junto a los motivos religiosos que influyeron en esta donación, no podemos obviar el trasfondo político del acto, pues la presencia de los monjes cluniacenses en estas tierras recién incorporadas a Castilla, y siempre reivindicadas por Navarra, aseguraría el control y la fidelidad al monarca castellano y a sus sucesores.

A la documentación medieval de este monasterio se puede aplicar buena parte de lo señalado hasta ahora con carácter general o respecto a algunos casos concretos. Para empezar, los textos de los primeros siglos de su existencia nos han llegado, generalmente, a través de copias y, a menudo, por medio de cartularios. Algunos de éstos fueron elaborados en fecha muy tardía, como el Cartulario o registro de privilegios, bulas y donaciones del Monasterio, conservado en el Archivo Histórico Nacional; fue redactado a principios del siglo XVIII, seguramente por un monje del mismo cenobio. Tanto este Cartulario como el que se encuentra en el Archivo del Hospital Tavera de Toledo, escrito hacia 1744 por el monje najerense Juan Blesa, copian los documentos siguiendo un estricto orden cronológico y sin hacer comentarios de carácter diplomático; en ningún momento expresan dudas de la veracidad de los documentos que entonces se guardaban en el archivo del monasterio, muchos de los cuales se perdieron definitivamente en el abandono forzado del recinto por los monjes, como consecuencia de la desamortización de Mendizábal. El conte-

${ }^{26}$ Publicado como Liber Testamentorum Ecclesiae Ovetensis, Barcelona, 1995, realizando la prof. $\mathrm{M}^{a}$-.J. Sanz Fuentes el estudio paleográfico, la edición diplomática y los índices. Estudio filológico de José Antonio VALDÉS GALLEGO, El Liber Testamentorum Ovetensis. Estudio filológico y edición, Oviedo, 2000. Interesante como síntesis magistrales de sus aportaciones a este libro: $M^{a}$.J. SANZ FUENTES, «Cartularios» y «El lenguaje de los documentos falsos».

27 Sobre la documentación najerense me remito a mis propios trabajos: Santa María la Real de Nájera. Siglos XI-XIV, Madrid, 1987, 3 vols.; Colección documental de Santa María de Nájera (Siglos X-XIV), Tomo I, San Sebastián, 1991; Colección documental de Santa María de Nájera, siglo XV. Regesta documental, Logroño, 2011. 
nido de estos cartularios es muy semejante, y son pocos los documentos que se recogen en uno de ellos y no en el otro. También en el monasterio de Santo Domingo de Silos se conserva un códice, elaborado también tardíamente, que copia buena parte de la primera documentación najerense, sin aportar ningún documento nuevo respecto a los contenidos en los cartularios citados anteriormente.

Muy anterior en su elaboración y más breve en su contenido es el cartulario conservado en el monasterio de monjas bernardas de Santa María de Cañas; redactado a principios del siglo XIII, copia, sin orden cronológico 30 documentos reales ${ }^{28}$ comprendidos entre los años 923 y 1209. Se trata, por tanto, de algunos de los textos más emblemáticos de la historia del cenobio al referirse a los tiempos fundacionales y a las primeras donaciones regias.

Estas recopilaciones tienen explicación diferente de acuerdo con la fecha de elaboración. Las tres primeras, redactadas en el siglo XVIII, pretendían recoger toda la documentación del monasterio, de forma ordenada y siguiendo un criterio cronológico; de esta manera se facilitaba su consulta y se preservaban los textos por temor a posibles pérdidas. Por el contrario, el conservado en el cenobio de Cañas se encuadra en el largo pleito que el monasterio najerense sostuvo con el obispo de Calahorra, entre mediados del siglo XI y principios del XII; por ello, se recopilaron los documentos considerados más significativos para defender la postura de los monjes en ese debate.

Al analizar los Cartularios y otros textos najerenses se plantea como primera cuestión determinar si fue abundante la falsificación documental en este cenobio; y la primera idea que surge en relación con ello es la fama de falsificadores que tradicionalmente se atribuye a los monjes cluniacenses ${ }^{29}$. Y no resulta fácil en este caso desmontar esa reputación, ya que son abundantes los documentos, especialmente de origen real, que deben ser calificados de falsos (al menos falsos diplomáticos), interpolados o que plantean dudas sobre su elaboración.

Pero, por si esto fuera poco, nos encontramos con otro agravante: en 1169 el prior Raimundo fue acusado de falsificar, previo pago, unas cartas atribuidas al arzobispo de Tarragona, legado pontificio, por medio de las cuales se le nombraría abad de San Millán de la Cogolla, alegando que el prior que en ese momento estaba la frente del mismo se quería retirar. No se trata de una simple sospecha, sino de un hecho probado, ya que el papa Alejandro III encargó al arzobispo de Santiago y a sus sufragáneos que amonestaran al culpable y, como castigo, lo recluyeran en Cluny ${ }^{30}$.

${ }^{28}$ En realidad son 32 los documentos recogidos, pero dos lo están por duplicado; este hecho indica que no había un plan previo en el momento de redactar el cartulario y explica también el desorden cronológico de los textos copiados.

${ }^{29}$ C. REGLERO DE LA FUENTE, Cluny en España. Los prioratos de la provincia y sus redes sociales (1073-ca. 1270), León, 2008, p. 143.

30 M. CANTERA MONTENEGRO, Santa María la Real de Nájera, II, doc. 72; Colección documental de Santa María de Nájera, I, doc. 72. Este asunto se analiza en: J.Ch. BISKHO, «El abad Radulfo de 
No es posible analizar estas falsificaciones documentales (y utilizo aquí el término falsificación en sentido amplio; es decir, falsificación diplomática, aunque el contenido sea auténtico) desde el punto de vista paleográfico, ya que no se conserva en ningún caso el documento original. Sin embargo, hay otros elementos que delatan una modificación posterior a la pretendida fecha de concesión: preámbulos demasiado extensos y ampulosos para el momento de la supuesta redacción, errores cronológicos difíciles de justificar, delimitación demasiado precisa de los linderos de las propiedades, etc.

Sin duda, uno de los textos más emblemáticos del monasterio de Santa María de Nájera es el de su fundación y dotación por el monarca García III el de Nájera, fechado el 12 de diciembre de $1052^{31}$. Por supuesto, no se conserva el original, aunque posiblemente se intentó hacer pasar por tal alguna de las copias elaboradas en el siglo XII. Los ejemplares más cercanos a la fecha de 1052 son un pergamino conservado en el Archivo Catedralicio de Calahorra y otro en la Real Academia de la Historia. Este último fue descrito por Fidel Fita cuando pertenecía a don Pablo Bosch, quien lo donó a la Academia en $1915^{32}$. Este pergamino está decorado con una orla miniada retocada en 1587, y representa en la parte superior a la Virgen y al ángel en el momento de la Anunciación, con las leyendas Ave Sponsa Dei, replet te gratia celi y Sum Domini famula, fiat mihi nunc tua dicta. En la parte inferior se representa a los fundadores, los reyes García y Estefanía, con las leyendas Haec sunt Garsiae verbis firmata Mariae y Nititur hoc propria fieri coniux Stephania. Entre los fundadores está representada la iglesia: de tres naves, siendo la central más alta que las laterales; de bóvedas de cañón y la central representada como de herradura muy cerrada. La copia del Archivo del Hospital Tavera reproduce estas figuras, lo que indica claramente que copió el texto de este documento.

Posiblemente sea más cercano al original el texto del archivo calagurritano ${ }^{33}$, pues omite el prólogo largo y rimbombante de las otras copias, que denota la reelaboración del texto a mediados del siglo XII. En todo caso, podemos afirmar

Cluny y el prior Humberto de Carrión, "camerario" de España: tres cartas inéditas de hacia 1174", en Anuario de Estudios Medievales, 1 (1964), p. 208; M. CANTERA MONTENEGRO, Santa María la Real de Nájera I, p. 103 y 237; y en C. REGLERO DE LA FUENTE, Op. cit., p. 123. El Papa en su escrito amenazaba al prior con la excomunión si en el plazo de tres meses no obedecía la orden de retiro al claustro de Cluny; y establecía que, si se mantenía en la desobediencia, el rey y las autoridades del Reino no debían acoger al culpable, sino expulsarlo de su tierra. Parece que el prior no obedeció la orden pontificia, pues Alfonso VII promulgó edicto de destierro contra él, y le prohibió toda administración de bienes eclesiásticos en su Reino (M. CANTERA MONTENEGRO, Santa María la Real de Nájera, II, doc. 73; y Colección documental de Santa María de Nájera, I, doc. 73).

${ }^{31}$ M. CANTERA MONTENEGRO, Santa María la Real de Nájera, II, doc. 10; Colección documental de Santa María de Nájera, I, doc. 10.

32 "Santa María de Nájera. Estudio crítico", en Boletín de la Real Academia de la Historia, XXVI (1895), pp. 155-202. Tesoros de la Real Academia de la Historia, Madrid, 2001, p. 324.

${ }_{33}$ Éste parece ser el que sigue Antonio de YEPES, Coronica general de la Orden de San Benito, patriarca de religiosos, Valladolid, VI, escrit. XXI, fol. 463 [reed. Madrid, 1960, 3 vols.]. 
que el acto de la fundación y dotación por parte de García III es seguro, aunque los textos hayan sido rehechos e interpolados posteriormente ${ }^{34}$.

Pero éste no es, desde luego, el único documento falsificado en la colección del cenobio najerense: la mayoría de los privilegios reales concedidos a lo largo de los siglos XI y XII fueron, posiblemente, objeto de alguna manipulación, más o menos amplia, aunque cabe pensar que el contenido es verdadero. Muchos de estos textos, de concesión o confirmación de donaciones realizadas por monarcas navarros y castellanos, fueron copiados en el citado Cartulario de Santa María de Cañas; sin embargo, no se copió el de la fundación del cenobio; a primera vista, esto parece extraño, pero realmente no lo es tanto si relacionamos esta ausencia con el litigio que se estaba desarrollando en estos años entre el cenobio najerense y el obispo calagurritano.

El origen remoto de este pleito ${ }^{35}$ hay que establecerlo en el año 923, cuando García I Sánchez, rey de Pamplona, reconquistó Nájera y restauró en esa localidad la sede episcopal de Calahorra, puesto que esta ciudad todavía estaba bajo dominio musulmán. El obispado najerense nunca se consideró una fundación nueva, sino la prolongación y traslado forzoso de la sede calagurritana. Cuando García III dotó Santa María de Nájera, le agregó la iglesia del Santo Sepulcro de Calahorra, antigua sede del obispado en esta ciudad, y el monasterio de Valpuesta, capital de la diócesis de ese nombre; de esta forma vinculaba la sede episcopal de Nájera-Calahorra a dicha iglesia.

Pocos años después de la fundación de Santa María, y tras la conquista de la ciudad y de La Rioja por Alfonso VI, este monarca castellano entregó a la Orden de Cluny ${ }^{36}$ la iglesia y todas sus posesiones. $Y$ este hecho es el origen inmediato de la disputa con el obispo, pues con la entrega del cenobio a la Orden francesa se arrebataban a su autoridad numerosos bienes, iglesias, derechos y otras propiedades que le pertenecían; además, Cluny gozaba de los privilegios de exención canónica y económica, lo que impedía toda intervención del obispo diocesano. Desde el primer momento, el obispo de Nájera-Calahorra mostró su disconformidad con esta donación; y la evidencia clara es que su nombre no figura entre los obispos confirmantes del documento de donación.

Si éste es, indudablemente, el motivo principal del pleito, no podemos olvidar que a lo largo del siglo XII fueron frecuentes en toda la Cristiandad los enfrentamientos entre obispos y monasterios, por defender éstos sus privilegios frente al reforzamiento de la autoridad episcopal, que se consolidaba con el nuevo Derecho canónico. Así, el conflicto entre el obispo calagurritano y el monasterio najerense

${ }^{34}$ I. RODRÍGUEZ DE LAMA, Colección diplomática medieval de La Rioja (923-1225), I, Logroño, 1979 , p. 375.

35 M. CANTERA MONTENEGRO, Santa María la Real de Nájera,I, pp. 233-251.

${ }^{36}$ M. CANTERA MONTENEGRO, Santa María la Real de Nájera, II, doc. 22; Colección documental de Santa María de Nájera, I, doc. 22. La conquista de La Rioja se produjo el año 1076; y la entrega de Santa María a Cluny el 1079. 
se centró, generalmente, en la percepción de los diezmos y tercias de las iglesias, que ambas partes necesitaban y reclamaban para sí: el obispo para reforzar su autoridad y el monasterio para mantener su independencia.

Durante todo el tiempo en que se desarrolló este pleito, los monjes cluniacenses de Nájera comprobaron el incondicional apoyo de los monarcas castellanos a su causa, y que se manifestó de forma especial en la confirmación de varios de sus privilegios. Entre estos documentos destacan las confirmaciones a Cluny y al cenobio najerense de sus propiedades y derechos que otorgaron Alfonso VII, el año 1155, y Alfonso VIII, en $1175^{37}$. Incluso aunque los textos hayan sido interpolados o alterados por los monjes, el favor regio es indudable. Quizás sea interesante señalar que ninguno de estos documentos está recogido en el Cartulario de Cañas, como tampoco el de fundación, aunque sí se incluyen otros textos de dudosa veracidad o, al menos, interpolados. También hay que señalar que el primero de estos documentos citados, el de Alfonso VII de 1155, está dirigido al monasterio y a su prior Raimundo, el mismo que unos años más tarde fue acusado, y parece que con razón, de falsario, hecho que da solidez a las dudas sobre la elaboración del texto.

Como ya he dicho antes, la falsificación o interpolación de diversos privilegios reales hay que relacionarla con este largo pleito: los monjes tratarían de reforzar las pruebas a su favor a medida que veían peligrar su posición con sentencias contrarias a sus intereses (como, por ejemplo, la de 1220 que entregaba al obispo la propiedad del monasterio) ${ }^{38}$. La sentencia definitiva que cerró el pleito fue dictada en 1223³9; gracias a ella, el cenobio conservó la mayoría de sus derechos, aunque se reconocieron también ciertas prerrogativas episcopales en diversas propiedades najerenses, así como el tercio de los diezmos de todas las iglesias que le pertenecían.

Volviendo al Cartulario de Cañas, y a la vista del pleito con el obispo calagurritano, creo que la justificación de no haber copiado en él el documento fundacional de Santa María de Nájera es que para el monasterio este texto no era especialmente relevante, ya que el obispo no reclamaba contra la fundación del cenobio ni contra los bienes en ella otorgados por el monarca navarro, sino contra su entrega a Cluny, pues fue este acto jurídico, que el obispo siempre calificó de injusto, el que le arrebató sus derechos sobre dichos bienes e iglesias. Por el contario, para el obispo este documento sí era importante, pues en él se habla claramente de la fundación por parte del monarca navarro de una comunidad de canónigos para atender al obispado y la vinculación, por tanto, de los numerosos bienes que for-

${ }^{37}$ M. CANTERA MONTENEGRO, Santa María la Real de Nájera, II, docs. 62 y 75, respectivamente; Colección documental de Santa María de Nájera, I, docs. 62 y 75.

${ }_{38}$ M. CANTERA MONTENEGRO, Santa María la Real de Nájera, II, doc. 125. Esta sentencia, sin embargo, no se ejecutó.

39 M. CANTERA MONTENEGRO, Santa María la Real de Nájera, II, doc. 144; fue ratificada por el papa Honorio III al año siguiente, como se recoge en el documento 147 de esta colección. 
maban parte de la dotación fundacional al diocesano y a dicha comunidad. Esto puede justificar la presencia de una copia del texto, bastante cercana a la dotación, en el Archivo Catedralicio de Calahorra.

Para el monasterio najerense serían, sin duda, más importantes los privilegios de confirmación otorgados por diversos monarcas, castellanos o navarros, especialmente los citados de Alfonso VII de 1155 y de Alfonso VIII de 1175. Si comparamos estos dos documentos y el de fundación, como en parte ha hecho Reglero de la Fuente ${ }^{40}$, podemos constatar la larga extensión y la detallada descripción de los bienes que hacen los atribuidos a García III y Alfonso VIII, frente al contenido más breve del de Alfonso VII; incluso habría que indicar el detallismo con el que el documento fundacional describe alguna de las propiedades donadas y los límites precisos de ciertas heredades incluidas en el texto (y ello ratifica su elaboración en fecha posterior a la pretendida de 1052).

El contenido de los tres textos no es exactamente igual, lo mismo que tampoco lo es el orden en el que aparecen los bienes descritos en ellos. No creo que esto sea un argumento de peso a favor de la falsificación de los documentos (como sí lo son otros elementos que luego señalaré), ya que no pretendían ser una confirmación literal uno del otro, sino que dichas confirmaciones se presentan independientemente incluso del hecho fundacional y de su primera dotación.

El documento de Alfonso VII es el más breve y todos los bienes incluidos en él están recogidos en el texto de 1052, a excepción de Santa Coloma, monasterio cercano a Nájera y cuya incorporación al cenobio najerense se produjo después de su dotación inicial. Efectivamente, este pequeño cenobio había sido restaurado el año 923 por Ordoño II tras la reconquista de esa ciudad ${ }^{41}$; donado en 1052 por García III a la alberguería aneja a Santa María, fue su viuda Estefanía quien lo donó definitivamente a este templo en su testamento ${ }^{42}$.

La falsificación del documento puede asegurarse por hechos como incluir entre los confirmantes a Rodrigo, obispo de Calahorra, aunque aparece titulado como obispo najerense. Su presencia avalando este acto no parece verosímil, pues ya estaba abierto el pleito y precisamente el obispo acababa de reclamar ante la Santa Sede unos derechos que este texto negaría, pues atribuye a la comunidad monástica la propiedad y diezmos de iglesias demandadas por el diocesano.

40 Op. cit., pp. 184-185.

${ }^{41}$ M. CANTERA MONTENEGRO, Santa María la Real de Nájera, II, doc. 2; Colección documental de Santa María de Nájera, I, doc. 2. Este documento también es un falso documental de fines del siglo $\mathrm{XI}$ o, más probablemente, de principios del XII; seguramente la falsificación se relaciona con el pleito con el obispo de Calahorra, para poder alegar una mayor antigüedad de derechos sobre dicho monasterio. Rodríguez de Lama (Colección, II, pág, 18, nota 1) considera pruebas de la falsificación la utilización de ciertas fórmulas que no corresponden al siglo X (como Dei gratia o el título de serenissimus dado a Ordoño II), así como la datación por el sistema de la Encarnación o el largo prólogo que abre el texto.

42 M. CANTERA MONTENEGRO, Santa María la Real de Nájera, II, docs. 9 y 18 respectivamente; Colección documental de Santa María de Nájera, I, docs. 9 y 18. 
También parece ratificar la hipótesis de la falsificación o interpolación del texto el que se incluya en él, entre los bienes confirmados, el monasterio de Santa María del Puerto, en Santoña (in Asturiis como afirma el documento). La referencia explícita a este cenobio resulta extraña, ya que, efectivamente, había sido donado en 1052 por García III; pero en 1156 el príncipe Sancho (futuro Sancho III de Castilla), que había suscrito el documento del año anterior, confirmó de nuevo Santa María del Puerto al cenobio najerense y a Cluny, explicando que después de la donación del monarca navarro el monasterio cántabro había pasado a poder real, aunque no explicaba cuándo, por qué o con qué motivo sucedió ${ }^{43}$.

No parece probable que ese cambio en la titularidad se produjese en el intervalo de meses que separan los privilegios de Alfonso VII y de su hijo. Cabría explicar este hecho, además de por la falsificación de uno u otro texto (o de los dos), por el deseo del príncipe de ratificar con su documento, y hacer más explícita, la devolución del cenobio que se habría realizado ya en 1155, o incluso antes; aunque de ser así, lo más normal es que lo hubiese hecho constar.

De todas formas, también cabe dudar de la veracidad documental del texto del príncipe Sancho, pues entre los confirmantes vuelve a aparecer Rodericus, Naxarensis episcopus, cuando tampoco es creíble que estuviese conforme con el acto reseñado; más bien, hay que pensar en la utilización de un modelo del que se copió la relación de testigos.

Por último, abordamos el documento de Alfonso VIII de 1175, el único de los tres analizados que fue confirmado por monarcas posteriores, desde Alfonso $\mathrm{X}$ hasta los Reyes Católicos ${ }^{44}$. Cabe plantearse por qué este texto sí fue confirmado y los otros dos no, cuando era habitual solicitar ese aval jurídico al inicio de cada reinado, y considerando que el documento fundacional marca el nacimiento del cenobio. ¿Quizás el monasterio no los presentó a la cancillería regia, pues no se consideraban especialmente relevantes para el monasterio (sobre todo por la vinculación que el documento fundacional establecía con el obispo)? O ¿serían efectivamente presentados para su confirmación y rechazados por la cancillería regia al detectar $\mathrm{o}$, al menos, sospechar la falsificación ( $\mathrm{y}$, de nuevo, la referencia más explícita sería para el documento de García III)? No podemos, dada la falta de documentación, inclinarnos a favor de una u otra hipótesis; en todo caso sí reiterar que el documento de Alfonso VIII fue confirmado por Alfonso X el Sabio casi un siglo después de su supuesta elaboración, sin que la cancillería detectase la manipulación que del texto se hizo; o quizás aunque se sospechase, porque el mo-

${ }^{43}$ M. CANTERA MONTENEGRO, Santa María la Real de Nájera, II, doc. 64; Colección documental de Santa María de Nájera, I, doc. 64.

${ }^{44}$ Alfonso X lo confirmó en 1272; Sancho IV en 1292 sobre el texto anterior; Alfonso XI en 1332 sobre el documento de Sancho IV; Pedro I en 1351, Juan I en 1379 y Enrique III en 1391, sobre el citado texto de Alfonso XI; Juan II, en 1407 y 1420, lo confirmó sobre el documento de Enrique III; y este último texto de Juan II sirvió de base para la confirmación de los Reyes Católicos de 1486 (M. CANTERA MONTENEGRO, Santa María la Real de Nájera, II, docs. 181, 203 y 261; y III, docs. 301, 342 y 398 ; e Idem, Colección documental... Regesta, docs. 44, 99 y 272). 
narca necesitaba en ese momento el apoyo de la comunidad y, en general, del estamento eclesiástico ante la difícil situación del trono ${ }^{45}$.

Hay que señalar que la relación de este monarca con Santa María de Nájera no se limitó a confirmar antiguos privilegios y a otorgar otros nuevos. También hubo una relación cultural, ya que precisamente el primer documento de Alfonso $X$ dirigido al cenobio najerense es un recibo de varios libros que el monasterio prestó al monarca ${ }^{46}$.

En todo caso, el documento de Alfonso VIII es más extenso que el de la fundación, incluyendo la referencia de algunas propiedades no mencionadas en dicho texto. La novedad de algunos de los bienes citados se explica porque su incorporación al cenobio najerense consta que se produjo en fecha posterior a 1052 (por ejemplo, Villalmondar, Alesón, Pedroso o Santa María de Estíbaliz); mientras que en otros casos tenemos aquí la primera noticia de su pertenencia a Santa María de Nájera.

Para Reglero de la Fuente ${ }^{47}$, ésta podría ser una de las pruebas de la falsificación o interpolación del texto; y a ello se añadiría el diferente orden en que aparecen citadas las propiedades donadas o confirmadas en los documentos anteriores, especialmente en comparación con el fundacional. Sin embargo, pienso que, sin descartar totalmente que estos hechos puedan reflejar la manipulación del texto y se refiera la situación existente en una fecha más tardía que la pretendida del documento, caben otras explicaciones. En primer lugar, se pudo producir la incorporación de algunas propiedades (lo más normal es que fuese por medio de donación) y que el texto que lo recogiese se haya perdido; o que, incluso, nunca haya existido, pues no podemos olvidar que el documento escrito no era todavía aval imprescindible de los actos jurídicos. En segundo lugar, no creo que el orden de las propiedades consignadas sea un hecho especialmente relevante, ya que el documento de 1175 no se presenta como confirmación del documento fundacional, sino de los bienes que en ese momento tenía Santa María de Nájera.

Sin embargo, sí es relevante el hecho que destaca este mismo autor respecto a muchos de los bienes recogidos tanto en 1052 como en 1175: mientras en el primero de los textos se alude de forma expresa a las villas (por ejemplo en el caso de Sojuela), en 1175 se habla de las iglesias o monasterios como sujetos principales, y las villas como anejos de los primeros. Es decir, en ese momento lo importante era la propiedad sobre dichas iglesias o monasterios; esta diferencia

45 En este sentido, y en relación con el ámbito geográfico de La Rioja, M. CANTERA MONTENEGRO, «Alfonso X y los monasterios y cabildos de La Rioja», en Alfonso X el Sabio. Vida, obra y época, I, Madrid, 1989, pp. 153-175.

46 M. CANTERA MONTENEGRO, Santa María la Real de Nájera, II, doc. 167; I, pp. 159-160; y Alfonso X, p. 163. Algunos de estos libros fueron utilizados en la redacción de la Crónica General de España.

47 Op. cit., p. 184. 
está lógicamente en relación con el pleito con el obispo de Calahorra por los diezmos de esos templos.

Hay, por último, otro elemento que avala la tesis de la interpolación o falsificación del documento de 1175: la inclusión entre las propiedades najerenses de la villa de Torrecilla de Cameros, cuando el cenobio najerense obtuvo esta villa en 1179, mediante la permuta realizada con Alfonso VIII de dicha villa por la de Valluércanes ${ }^{48}$. Ello refleja que el documento de 1175 fue redactado, o al menos retocado, después de la fecha señalada; y que en el momento de su elaboración se tenía constancia de la posesión de la villa, pero no se comprobó en qué fecha se había producido su incorporación al patrimonio najerense.

Aunque estos tres documentos sean muy representativos de la documentación de Santa María de Nájera y de la manipulación de los textos, no son los únicos que plantean dudas sobre su autenticidad. Realmente son sospechosos de haber sido manipulados casi todos los primeros documentos del monasterio, al menos hasta finales del siglo XII. De todas formas, hay que insistir en que la falsificación posiblemente fue más formal que de contenido; es decir, se redactaron diplomas a los que se atribuía una antigüedad que no era cierta, pero dando testimonio de un hecho verdadero.

Es el caso del citado documento de Ordoño II sobre Santa Coloma; o los de Sancho II Garcés de $972^{49}$, entregando la villa de Cirueña al monasterio de San Andrés de esa localidad y concediendo poco después al lugar un fuero o carta vecinal; o el de 1046, por el cual García III donó a su mujer Estefanía el monasterio de Santa Coloma ${ }^{50}$; y el de Sancho IV de Peñalén, de fecha cercana a 107451, otorgando algunos bienes a la comunidad de Cirueña.

El propio documento de entrega de Santa María de Nájera a la Orden de Cluny en $1079^{52}$ es también dudoso en su aspecto formal o diplomático, aunque insisto, y especialmente en este caso, que la falsedad diplomática no supone la falsedad del contenido. Así, el obispo nunca puso en duda la veracidad de la entrega a Cluny, sino que demandaba contra la injusticia que se derivaba de ese hecho.

${ }^{48}$ M. CANTERA MONTENEGRO, Santa María la Real de Nájera, II, doc. 80; Colección documental de Santa María de Nájera, I, doc. 80.

49 M. CANTERA MONTENEGRO, Santa María la Real de Nájera, II, docs. 3 y 4; Colección documental de Santa María de Nájera, I, docs. 3 y 4.

${ }^{50}$ M. CANTERA MONTENEGRO, Santa María la Real de Nájera, II, doc. 8; Colección documental de Santa María de Nájera, I, doc. 8.

51 M. CANTERA MONTENEGRO, Santa María la Real de Nájera, II, doc. 19; Colección documental de Santa María de Nájera, I, doc. 19. En la redacción del texto se mezcla el latín y el romance; además de ser una prueba de la falsificación, al menos formal, nos habla de la necesidad de hacer comprensible su contenido en un momento más tardío de su supuesta redacción.

${ }_{52}$ M. CANTERA MONTENEGRO, Santa María la Real de Nájera, II, doc. 22; Colección documental de Santa María de Nájera, I, doc. 22. 
También plantea dudas la donación que en 1142 hizo Alfonso VII de las villas de Cuevacardidel y Villalmondar al cenobio najerense ${ }^{53}$; $y$, como ya he dicho antes, podríamos alargar la relación con todos los documentos reales contenidos en la colección najerense hasta el siglo XIII.

\section{CONCLUSIÓN}

Para concluir, sólo queda decir que Santa María de Nájera no es una excepción ni un caso especial en cuanto a la falsificación documental durante la Edad Media. Y que, como en otros casos, nos encontramos ante todo con la manipulación de diplomas reales, empezando por el de su fundación y siguiendo por las principales confirmaciones regias de su patrimonio y privilegios más destacados.

En la mayoría de los casos, estas reelaboraciones están en relación con el pleito que el cenobio mantuvo con el obispo de Calahorra por el disfrute de rentas en las iglesias y otras propiedades del monasterio. Por ello, el momento álgido de las falsificaciones se produce coincidiendo con el desarrollo de dicho litigio, en el siglo XII, y especialmente en su segunda mitad.

También hay que destacar que, a pesar de la manipulación de los textos, de su falsedad formal, no podemos dudar de la veracidad de contenido; por tanto, nos hayamos ante documentos falsos diplomáticos, pero no ante falsos históricos.

${ }^{53}$ M. CANTERA MONTENEGRO, Santa María la Real de Nájera, II, doc. 79; Colección documental de Santa María de Nájera, I, doc. 79. Así lo indica C. REGLERO DE LA FUENTE, Op. cit., p. 128. 